\title{
High-fidelity, infinite time constant calibrated pressure apexcardiogram and its correlation with high-fidelity left ventricular pressure ${ }^{\star \dagger}$
}

\author{
P SUDHAKAR REDDY, FRANK MENO, JAMES D O'TOOLE, \\ EDWARD I CURTISS, FRANKLIN W GRIFF
} From the Division of Cardiology, Department of Medicine, University of Pittsburgh School of Medicine,
and Presbyterian-University Hospital, Pittsburgh, Pennsylvania, USA

SUMMARY A technique of recording the pressure apexcardiogram by means of a high-fidelity piezoresistive transducer has been developed in our laboratory. It permits the quantification of pressure with which the transducer is applied to the chest wall as well as the pressure changes during a cardiac cycle. In this preliminary report, apexcardiographic pressures were compared with simultaneously recorded high-fidelity left ventricular pressure in 32 patients. There were no significant differences in the timing of the left ventricular systolic upstroke and the " $\mathrm{O}$ " point. Peak $\mathrm{dP} / \mathrm{dt}$ of the apexcardiogram occurred $(10 \pm 13 \mathrm{~ms})$ significantly earlier than the intraventricular pressure recordings. Though there was a correlation between developed diastolic pressure (end-diastolic minus early diastolic pressure) measured by the apexcardiogram $(20 \pm 14 \mathrm{mmHg})$ and intraventricular pressure recordings $(11 \pm 6 \mathrm{mmHg})$, the former was significantly higher. Pressure overshoots in early and late diastole contributed to this overestimation by the apexcardiogram but the relative contribution of each phase varied from patient to patient. There was a similar correlation between systolic pressures, but this index tended to be underestimated by the apexcardiogram.

The data suggest that the apical impulse is not solely caused by the passive transmission of left ventricular pressure. The convenient, direct method of measuring application and developed pressure at the apex described in this report permits scientific investigation of the forces responsible for genesis of this impulse and its alteration in pathological states.

Conventional apexcardiography provides a record of relative displacement, that is, displacement of the chest wall enclosed by the transducer pick-up cup in relation to the surrounding area at the rim of the cup. ${ }^{2}$ The impulse cardiography of Mounsey ${ }^{3}$ and kinetocardiography of Eddleman ${ }^{4}$ record absolute chest wall movement at the point of measurement in relation to a fixed point in space. Both relative and absolute displacement recordings are significantly modified by physical properties of the chest wall and the application or loading pressure. Therefore, it has been felt for some time that the measurement of the force or pressure which causes the displacement would be more meaningful

^ Supported in part by a grant-in-aid from the Western Pennsylvania Heart Association.

† Presented at the 51st Annual Scientific Session of the American Heart Association, 13-16 November 1978, Dallas, Texas, USA.

Received for publication 22 October 1979 and reliable. The basic principles underlying this technique have been elucidated by Willems et al. ${ }^{5}$ using either fluid-filled pressure transducers or Telco catheters in dogs and fluid-filled pressure transducers in man. Gleichmann et al., ${ }^{6}$ and Witte and Heublen ${ }^{7}$ used strain-gauge transducers in human subjects to measure the force on the chest wall at the point of apical impulse, but, unfortunately, their technique did not permit measurement of application pressure, which must be known to calibrate the system properly.

We have developed a technique of recording the apexcardiogram by means of a high-fidelity piezoresistive pressure transducer. It permits quantification of both application pressure as well as pressure changes during the cardiac cycle. In this preliminary report, we compare the results of external pressure recordings with intraventricular pressure recordings obtained by a similar transducer. 


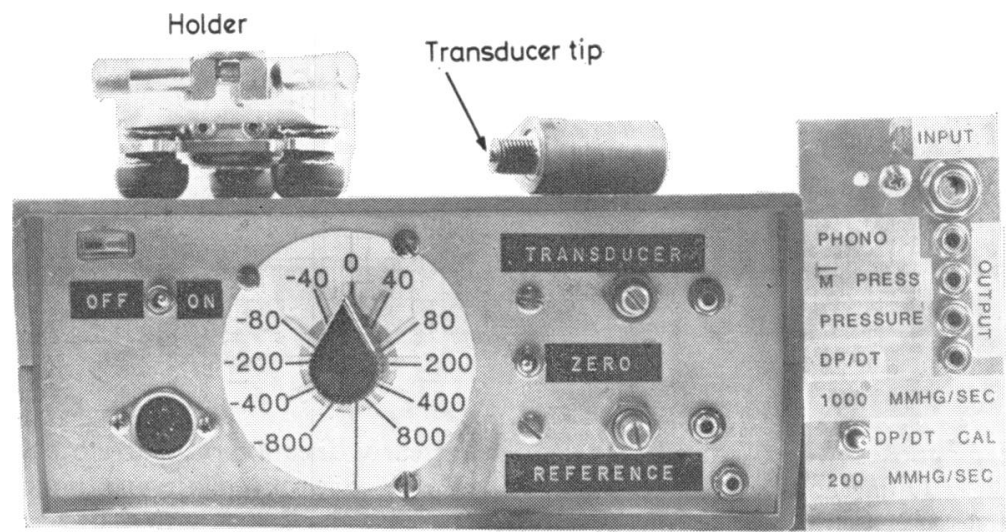

Fig. 1 Prototype of pressure apexcardiographic system used in this study. The positive numbers on the amplifier are used to calibrate the pressure signal while the negative numbers on the lefthand side indicate the negative pressure applied to offset the loading pressure.

\section{Subjects and methods}

Our apexcardiographic transducer (Fig. 1) is a piezo-resistive strain gauge mounted on a thin stainless steel diaphragm approximately $2 \mathrm{~mm}$ in diameter. The dynamic range of the transducer is from zero to $1520 \mathrm{mmHg}$ with a flat frequency response from zero to $10000 \mathrm{~Hz}$.

The four-leg active bridge is supplied with a highly regulated direct current voltage of \pm 3 volts. The signal voltage is amplified by an instrumentation amplifier so that an output of 1 volt is equivalent to a pressure of $100 \mathrm{mmHg}$. The system is calibrated with air pressure using a sphygmomanometer.

The voltage generated by the total pressure (which is the sum of static pressure and dynamic pressure) is fed into the summing junction of an operational amplifier. A negative voltage is then applied to offset the output so that the " 0 " point of the apexcardiogram is close to the baseline. The loading pressure is determined from the negative voltage applied since the latter is calibrated ( 1 volt $=$ $100 \mathrm{mmHg}$ ). The negative voltage opposing the loading pressure could be applied in steps of 0,40 , $80,200,400$, and $800 \mathrm{mmHg}$. The signal is then passed through a low-pass Butterworth filter with $40 \mathrm{db} /$ decade roll-off above $25 \mathrm{~Hz}$ and electronically differentiated and calibrated ( 1 volt $=1000 \mathrm{mmHg} / \mathrm{s}$ ) to measure $\mathrm{dP} / \mathrm{dt}$ of the apexcardiogram. The undifferentiated signal is used to record the apexcardiographic pressure.

With the patient in the semi-left lateral recumbent position, the apexcardiograph transducer was held to the chest wall at the point of maximal apical impulse by means of a three-legged holder fastened to the patient with a three-way elastic strap. The transducer was advanced in the centre of the holder by means of a screw; thus, the loading pressure could be controlled by adjusting the advancement of the transducer. The apexcardiogram was recorded with a loading pressure of 200 and $400 \mathrm{mmHg}$. Loading pressure was increased beyond $200 \mathrm{mmHg}$ until the maximal amplitude of the systolic wave was obtained. Respiration was held at the point where maximal amplitude was achieved.

Simultaneous recordings of the apexcardiogram, left ventricular pressure, and their first derivatives were recorded in 32 patients ( 23 men, nine women) undergoing cardiac catheterisation. Their mean age

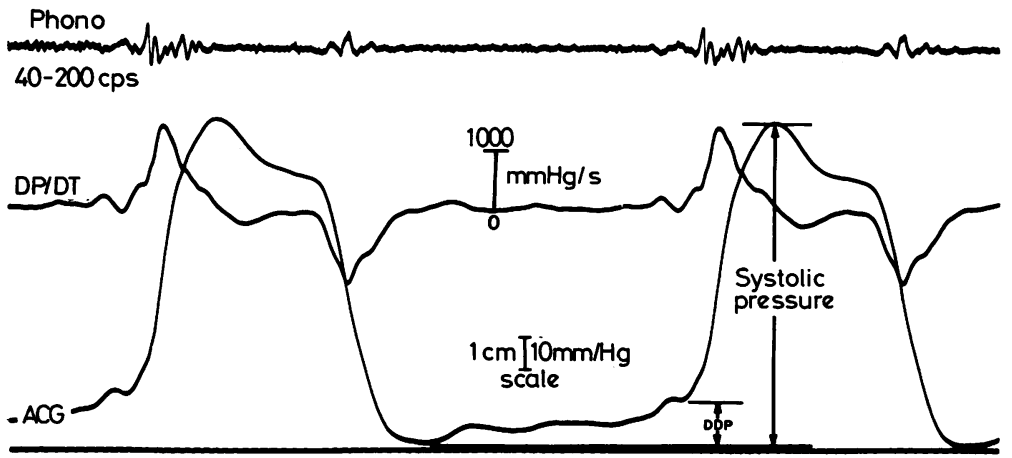

Fig. 2 Calculation of pressures from the apexcardiogram ( $A C G$ ). The signal has also been processed to yield the first derivative of pressure $(d P / d t)$ and $a$ phonocardiogram (phono). Developed diastolic pressure (DDP) is measured from the early diastolic nadir to the onset of the systolic wave upstroke. Systolic pressure is measured from the early diastolic nadir to the peak of the systolic wave. 
Fig. 3 Identification of the onsets of the systolic wave upstroke and "0" points in simultaneous recordings of $A C G$ and left ventricular $(L V)$ pressure and their first derivatives $(d P / d t)$. Systolic upstroke onsets were directly identified in the pressure traces. The " 0 " point was the point where a $d P / d t$ of zero $\mathrm{mmHg} / \mathrm{s}$ was reached in early diastole.

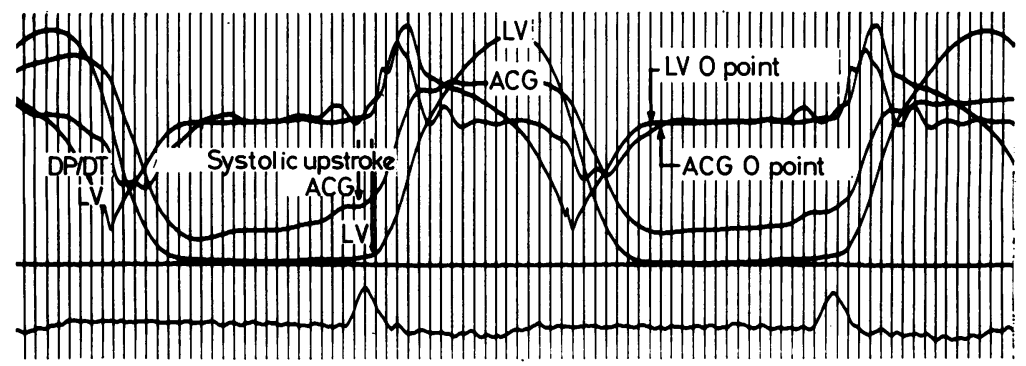

was $52 \pm 14$ years $( \pm S D)$. Their diagnoses were: atherosclerotic heart disease in 12, valvular aortic stenosis in six, aortic regurgitation in seven, mitral regurgitation in four, cardiomyopathy in two, and coarctation of the aorta in one. Three patients were in atrial fibrillation, and the remainder were in sinus rhythm. Left ventricular pressure was recorded with a Millar micromanometer catheter. Micromanometer pressure was corrected for the effect of gravity by superimposing its pressure over the fluid-filled pressure during slow rates of pressure change in diastole. The zero reference level for pressure measurement was $5 \mathrm{~cm}$ below the sternal angle.

For each patient, the following measurements represented an average of five consecutive cardiac cycles and were obtained from recordings taken at a paper speed of 100 to $200 \mathrm{~mm} / \mathrm{s}$, with $20 \mathrm{~ms}$ time lines. Developed diastolic pressure of the apexcardiograph was measured from the " 0 " point to the onset of the systolic wave upstroke (Fig. 2). Left ventricular developed diastolic pressure was left ventricular end-diastolic pressure minus mini- mum left ventricular early diastolic pressure. Since the left ventricular early diastolic nadir was not a temporally distinct point in most patients, zero $\mathrm{dP} / \mathrm{dt}$ in early diastole was selected as the " 0 " point for both the left ventricle and apexcardiogram in all cases (Fig. 3 and 4). Systolic pressure of the apexcardiogram was measured from the " 0 " point to the peak of the systolic wave (Fig. 2); apexcardiograph systolic pressure was not measured in seven patients since recordings were obtained only at high gain in these subjects.

Left ventricular and apexcardiograph pressure recordings were compared with respect to the occurrence of the onset of the systolic upstroke, " 0 " point and peak $\mathrm{dP} / \mathrm{dt}$. The following comparisons of pressures were made: left ventricular enddiastolic pressure versus left ventricular developed diastolic pressure; left ventricular end-diastolic pressure versus apexcardiograph developed diastolic pressure; left ventricular developed diastolic pressure versus apexcardiograph developed diastolic pressure; left ventricular systolic pressure versus apexcardiograph systolic pressure; left ventricular
Fig. 4 Simultaneous left ventricular and $A C G$ pressure and $d P / d t$. The onsets of the systolic upstroke and " 0 " points are simultaneous. Developed diastolic pressure of the $A C G$ is greater than $L V$ developed diastolic pressure. ACG systolic pressure is less than the $L V$ systolic pressure, but peak $d P / d t$ 's are identical.

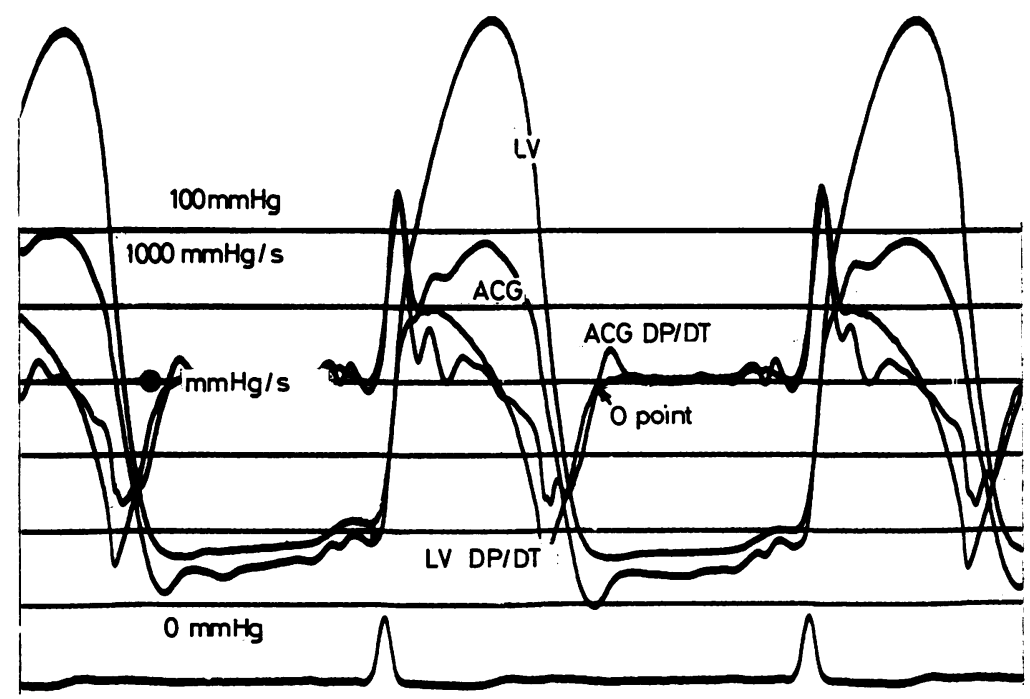


peak $\mathrm{dP} / \mathrm{dt}$ versus apexcardiograph peak $\mathrm{dP} / \mathrm{dt}$. The comparison was made using paired data and Student's $t$ test. The null hypothesis tested statistically was no significant difference between pairs. For these data, Pearson's correlation coefficient was derived and regression analysis performed assuming a linear relation. Only correlation coefficients significantly different from zero are reported.

\section{Results}

\section{ONSET OF LEFT VENTRICULAR SYSTOLIC WAVE}

The onsets of the systolic waves in the apexcardiogram and left ventricular pressure traces were not significantly different. They were simultaneous in 24 of the 32 patients (Fig. 4), occurred $104040 \mathrm{~ms}$ earlier in the apexcardiogram of six patients (Fig. 3), and were earlier by $20 \mathrm{~ms}$ in the left ventricular pressure traces of two patients.

"0" POINT

The " 0 " point of the apexcardiogram was simultaneous with left ventricular pressure in 22 patients (Fig. 4), preceded it by 10 to $40 \mathrm{~ms}$ in eight patients, and followed it by 20 and $40 \mathrm{~ms}$, respectively, in two patients (Fig. 3). The mean difference $( \pm$ SD) was $5( \pm 16) \mathrm{ms}$ which was not statistically significant.

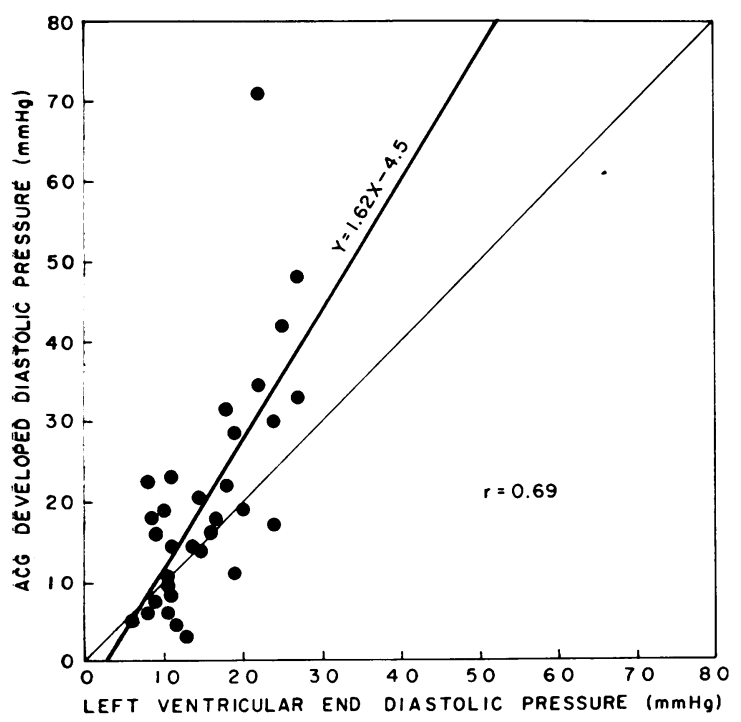

Fig. 5 Left ventricular end-diastolic pressure versus developed diastolic pressure determined from the apexcardiogram. The heavy solid line is the regression line, and the light solid line is the line of identity.

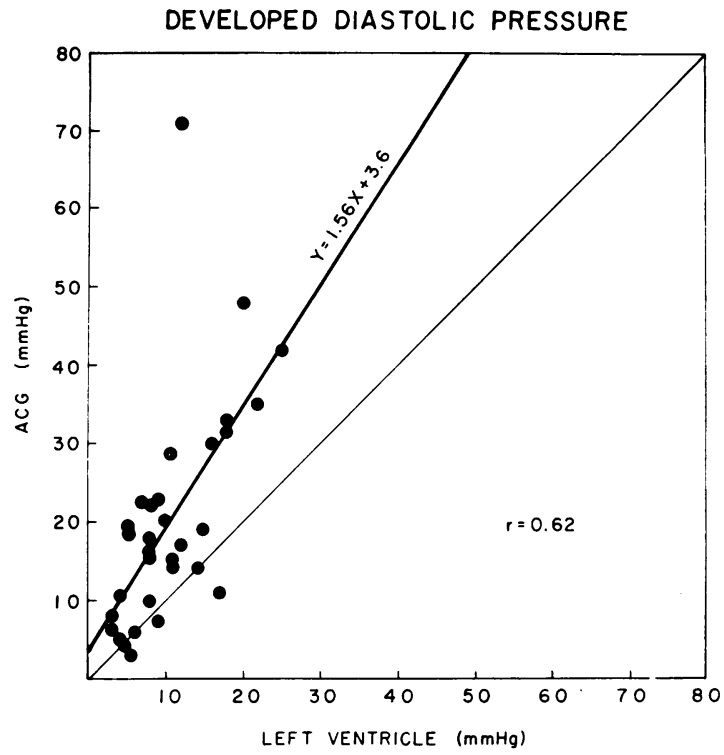

Fig. 6 Left ventricular developed diastolic pressure versus apexcardiogram developed diastolic pressure. The heavy solid line is the regression line and the light solid line is the line of identity.

\section{OCCURRENCE OF PEAK DP/DT}

Peak $\mathrm{dP} / \mathrm{dt}$ of the apexcardiogram preceded that of left ventricular pressure by 5 to $35 \mathrm{~ms}$ in 20 patients (Fig. 3), occurred simultaneously with it in nine patients (Fig. 4), and followed it by 5 to $15 \mathrm{~ms}$ in three patients (mean $( \pm S \mathrm{SD}), 10( \pm 13) \mathrm{ms}$; $\mathrm{p}<0.001$ ).

\section{DIASTOLIC PRESSURE}

Left ventricular end-diastolic pressure in the 32 patients ranged from 6 to $27 \mathrm{mmHg}$ (mean $\pm \mathrm{SD}=$ $15 \pm 6 \mathrm{mmHg}$ ). Developed diastolic left ventricular pressure ranged from 3 to $22 \mathrm{mmHg}$ (mean $\pm \mathrm{SD}=$ $11 \pm 6 \mathrm{mmHg}$ ) and though this correlated with left ventricular end-diastolic pressure $(r=0.79)$, the two were significantly different $(p<0.001)$. The developed diastolic pressure of the apexcardiogram ranged from 3 to $71 \mathrm{mmHg}$ (mean $\pm S D=20 \pm 14$ $\mathrm{mmHg}$ ) and correlated with left ventricular enddiastolic pressure $(r=0.69)$ (Fig. 5) and left ventricular developed diastolic pressure $(r=0.62)$ (Fig. 6), but was systematically higher than both ( $p<0.025$ and $p<0.001$, respectively.)

Left ventricular and apexcardiographic pressure contours could be superimposed during middiastolic slow rates of pressure change in 22 patients (Fig. 7). In 16 of these 22, the developed diastolic pressure of the apexcardiogram exceeded that of the left ventricle by 1 to $18 \mathrm{mmHg}$ (mean $\pm \mathrm{SD}=$ 
Fig. 7 Simultaneous tracings of apexcardiogram and left ventricular pressures with superimposition of pressures during slow rates of pressure change in mid-diastole. The tracing at the top is the electrocardiogram. The apexcardiogram demonstrates a negative "overshoot" in early diastole and a positive "overshoot" at end-diastole.

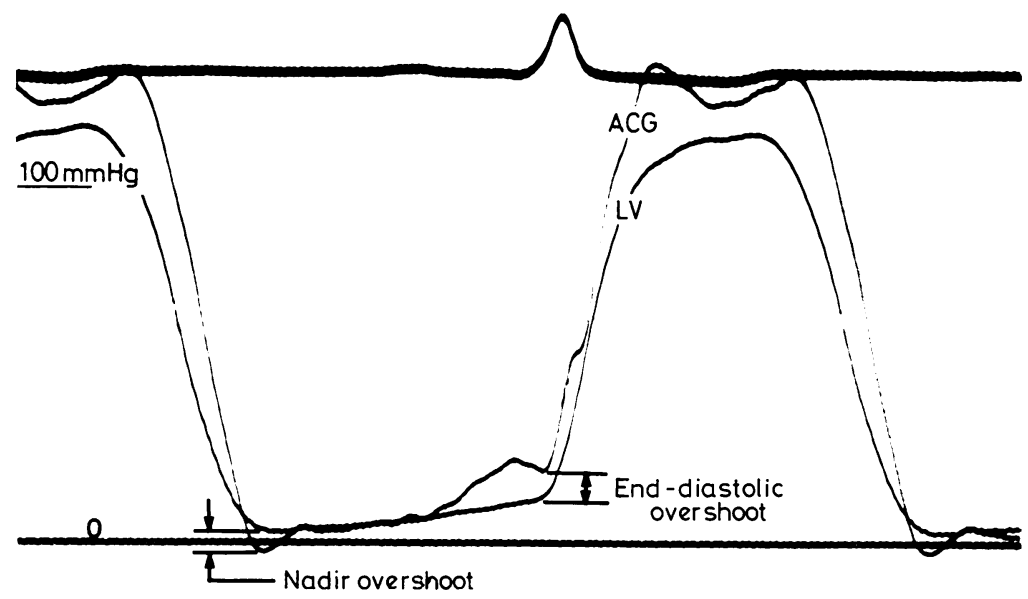

$11 \pm 5 \mathrm{mmHg}$ ). In five and four of the 16 , this overestimation by the apexcardiogram was totally accounted for by early and late diastolic "overshoots", respectively. In the remaining seven patients, overshoots occurred at both points.

SYSTOLIC PRESSURE (Fig. 8)

Left ventricular systolic pressure in 25 patients ranged from 87 to $280 \mathrm{mmHg}$ (mean $\pm \mathrm{SD}=$ $160 \pm 50 \mathrm{mmHg}$ ) and apexcardiographic systolic pressure varied from 60 to $684 \mathrm{mmHg}$ (mean \pm SD $=154 \pm 129 \mathrm{mmHg})(\mathrm{r}=0.69)$. Compared with left

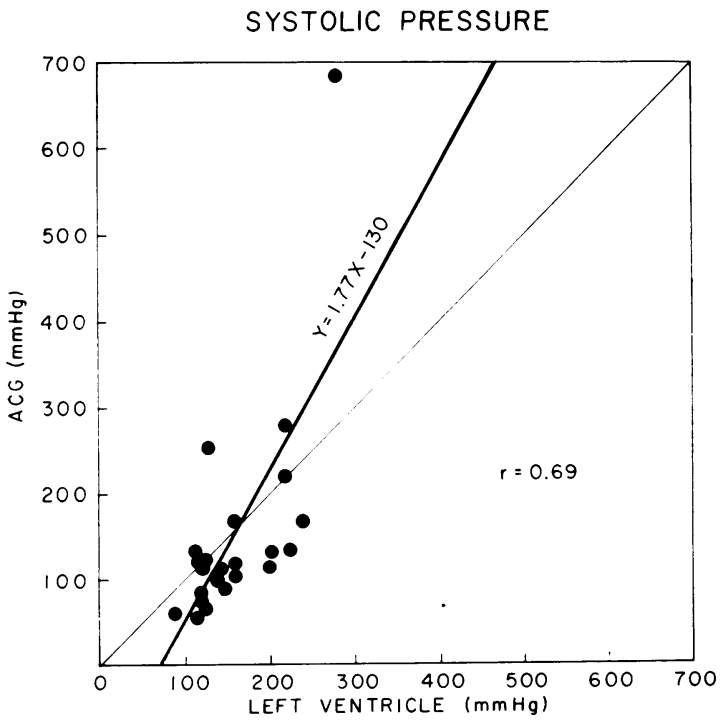

Fig. 8 Left ventricular systolic pressure versus apexcardiographic systolic pressure. The heavy solid line is the regression line and the light solid line the line of identity.

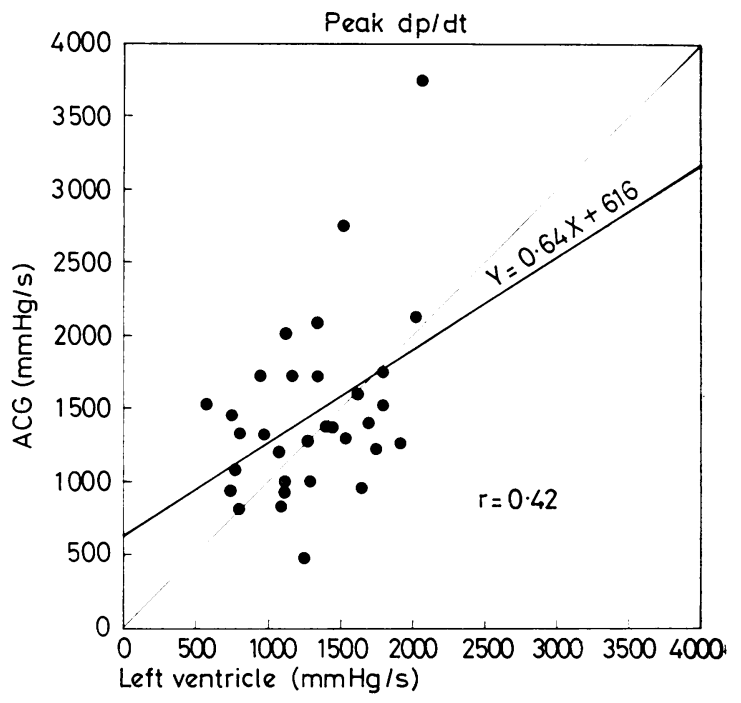

Fig. 9 Left ventricular peak $d P / d t$ versus apexcardiographic peak $d P / d t$. The heavy solid line is the regression line and the light solid line the line of identity.

ventricular systolic pressure, the apexcardiograph systolic pressure was lower by 10 to $85 \mathrm{mmHg}$ in 17 patients, higher by 3 to $404 \mathrm{mmHg}$ in five patients, and equal in three patients. The patient with the highest left ventricular systolic pressure had an apexcardiograph systolic pressure 684 $\mathrm{mmHg}$; with this patient excluded from the statistical analysis, apexcardiograph systolic pressure was significantly lower $(p<0.025)$ than intraventricular systolic pressure.

DP/DT (Fig. 9)

Left ventricular peak $\mathrm{dP} / \mathrm{dt}$ ranged from 576 to 
$2062 \mathrm{mmHg} / \mathrm{s}$ (mean $\pm \mathrm{SD}=1309 \pm 408 \mathrm{mmHg} / \mathrm{s}$ ) and apexcardiographic peak $\mathrm{dP} / \mathrm{dt}$ ranged from 477 to $3757 \mathrm{~mm} \mathrm{Hg} / \mathrm{s}$ (mean $\pm \mathrm{SD}=1456 \pm 620$ $\mathrm{mmHg} / \mathrm{s})$. Correlation between the two was poor $(r=0 \cdot 42)$.

\section{Discussion}

Calibrated pressure apexcardiography employing piezo-resistive transducers has several distinct advantages: (1) it permits quantification of the apical impulse in $\mathrm{mmHg}$ and is essentially independent of chest wall displacement. The latter depends on chest wall compliance, which may vary from patient to patient. It should be noted, however, that the pressure perceived by the external transducer at the apex is caused by both active dynamic forces originating from cardiac motion, as well as passive transmission of ventricular pressure; (2) it permits quantification of the application or loading pressure. The pressure apexcardiographic transducer head must be applied to the chest wall with sufficient pressure so that proper coupling is obtained between it and the underlying ventricle. Since both displacement ${ }^{3}$ and pressure ${ }^{5}$ measured by apexcardiography have been shown to be dependent upon loading pressure, measurement of the latter is crucial for the quantification of any apexcardiographic signal; (3) the system has an infinitely long time constant (zero to $20 \mathrm{kHz}$ band width), which circumvents the disadvantages of poor time-constant apexcardiographic recordings.

The method, however, has disadvantages and limitations: (a) it is not possible to record the apexcardiogram in all patients, though our experience has been that such failure occurs in patients whose apexcardiogram has not been obtainable by other techniques. (b) As with any apexcardiographic system, the position of the patient and placement of the transducer has a significant effect on the height of the signal, and both must be optimal to obtain the maximal impulse. (c) With this, our first model, we could quantify the loading pressure only in steps of $40,80,200,400$, and $800 \mathrm{mmHg}$. This did not allow the precise quantification which may be essential for acceptably reproducible measurements of loading pressure.(d) The transducers require careful handling since any irreversible deformation of the stainless steel diaphragm would modify the pressure calibration and any violent force applied to it (such as striking it on a hard surface) would destroy the transducer. (e) The system is relatively expensive.

When the pressure apexcardiogram was used to identify the onset of the left ventricular systolic upstroke, no significant differences in timing were found between this and internal left ventricular micromanometer pressure tracings. Previously, using fluid-filled catheter systems for recording left ventricular pressure, Inoue et al. ${ }^{8}$ found that the apexcardiograph upstroke preceded the onset of left ventricular pressure rise by an average interval of $17 \mathrm{~ms}$ though Tavel et al. ${ }^{9}$ reported no significant differences in timing. Using micromanometer catheters, Fabian et al. ${ }^{10}$ also found that the left ventricular pressure upstroke followed that of the apexcardiogram by $20 \mathrm{~ms}$ but our data are in agreement with the findings of Manolas et al. ${ }^{11}$ in humans and Willems et al. ${ }^{12}$ in dogs who reported no systematic differences in timing of these two events. While there may be no significant discrepancy between groups of patients, individual variations may be based upon more than methodological error. As suggested by Tafur et al. ${ }^{13}$ and Tavel et al. ${ }^{9}$ the initial portion of ventricular mechanical systole may be associated with a change in ventricular configuration unaccompanied by a rise in pressure. If this change in configuration results in an outward thrust, the upstroke of the apexcardiogram may precede the left ventricular pressure rise, but if it results in retraction, then the initial rise in pressure may not be perceived by the external transducer and the upstroke of the apexcardiogram may follow that of the left ventricular pressure.

The early diastolic nadir of the left ventricular pressure trace represents an equilibration point where the pressure rise in the left ventricle resulting from filling cannot be compensated by the pressure fall caused by active relaxation. The point is not very sharp in the pressure traces of most patients, particularly when recordings are made at a high paper speed of 100 to $200 \mathrm{~mm} / \mathrm{s}$. Since the equilibration point should be equal to zero $\mathrm{dP} / \mathrm{dt}$ in early diastole, measurements of the left ventricular pressure and the apexcardiogram were related to this reference point. They were identical or the apexcardiogram was earlier than the left ventricle except in a few cases. The earlier occurrence of the " 0 " point in the apexcardiogram may be a result of the relaxing but expanding heart causing a positive thrust on the chest wall while left ventricular pressure continues to fall.

Since there is no zero reference level, the pressure apexcardiogram is capable only of measuring changes in left ventricular diastolic pressure. If the externally recorded diastolic pressure changes were solely caused by passive transmission of left ventricular diastolic pressure, then both developed diastolic pressures should have been essentially equal. Though a correlation was found between apexcardiographic and left ventricular developed diastolic pressure, the former was systematically higher than 
the latter. Since apexcardiographic and left ventricular pressure contours appeared to be superimposable in most patients during middiastolic slow rates of pressure change, we attempted to determine the relative contributions of early and late diastolic overshoots to this overestimation. Examination of data in this group of patients showed that both negative early and positive late diastolic overshoots contributed to the higher developed diastolic pressure recorded in the apexcardiogram. The relative contribution of each phase varied, however, from patient to patient. In the present study, we did not attempt to determine which factors (ventricular volume, wall thickness, tension) were important in determining the magnitude and phase of these overshoots. This investigation is now possible since the loading pressure and pressure changes sensed by the apexcardiogram can be quantified.

Although a correlation was found between left ventricular and apexcardiographic systolic pressures, the latter tended to underestimate systolic pressure in the majority of patients. This probably results from loss of proper contact with the underlying ventricle as the chamber progressively decreases in size during systole. However, the apexcardiogram was higher than the left ventricular systolic pressure in five patients and this may be because of the ballistic force exerted by the heart against the chest wall during forward ejection of the stroke volume. In a few patients, these positive and negative forces may cancel each other completely so that equal systolic pressures are recorded in the apexcardiogram and left ventricle. It is possible that there would be a better correlation between internal and external pressure if they were measured at the time of aortic valve opening as suggested by Kesteloot et al. ${ }^{14}$ If this were the case, there should be a good correlation between external and internal peak $\mathrm{dP} / \mathrm{dt}$. We did not find such a correlation, casting doubt on this premise.

It is clear that differences exist between left ventricular pressure and pressure measured at the apex, suggesting that the apical impulse is not simply caused by passive transmission of internal pressures. The convenient, direct method of measuring application and developed pressures at the apex described in this report permits the scientific investigation of forces responsible for the genesis of this impulse and its alteration in pathological states.

\section{References}

1 Benchimol A, Dimond EG, Carson JC. The value of the apexcardiogram as a reference tracing in phonocardiography. Am Heart $\mathcal{F} 1961$; 61 : 485-93.

2 Benchimol A, Dimond EG. The normal and abnormal apexcardiogram. Its physiologic variation and its relation to intracardiac events. Am $\mathcal{f}$ Cardiol 1963; 12: 368-82.

3 Mounsey JPD. Inspection and palpation of the cardiac impulse. Prog Cardiovasc Dis 1967; 10: 187-206.

4 Eddleman EE, Willis K, Reeves TJ, Harrison TR. The kinetocardiogram. I. Method of recording precordial movements. Circulation 1953; 8: 269-75.

5 Willems JL, DeGeest H, Kesteloot $H$. A new approach to the recording of low frequency precordial vibrations. Acta Cardiol (Brux) 1971; 26: 263-76.

6 Gleichmann U, Kreuzer H, Loogen F, Wilke KH. Quantitative Messung von Kraft und Geschwindigkeit der Kraftenwicklung im apexkardiogramm. $Z$ Gesamte Exp Med 1968; 145: 278-88.

7 Witte J, Heublein B. The value of quantitative apexcardiography as compared to intracardiac functional diagnostics of the left ventricle. Bibl Cardiol 1975; 33: 133-7.

8 Inoue $\mathrm{K}$, Young GM, Grierson AL, Smulyan IT, Eich RH. Isometric contraction period of the left ventricle in acute myocardial infarction. Circulation 1970; 42: 79-90.

9 Tavel ME, Campbell RW, Feigenbaum H, Steinmetz EF. The apex cardiogram and its relationship to haemodynamic events within the left heart. $\mathrm{Br}$ Heart $\mathcal{F}$ 1965; 27 : 829-39.

10 Fabian J, Epstein EJ, Coulshed N. Duration of phases of left ventricular systole using indirect methods. Br Heart $\mathcal{F}$ 1972; 34: 874-81.

11 Manolas J, Rutishauser W, Wirz P, Arbenz U. Time relation between apex cardiogram and left ventricular events using simultaneous high-fidelity tracings in man. Br Heart $\mathcal{f} 1975$; 37: 1263-7.

12 Willems JL, DeGeest H, Kesteloot H. On the value of apex cardiography for timing intracardiac events. Am f Cardiol 1971; 28: 59-66.

13 Tafur E, Cohen LS, Levine HD. The normal apex cardiogram. Its temporal relationship to electrical, acoustic, and mechanical cardiac events. Circulation $1964 ; 30: 381-90$.

14 Kesteloot H, Denef B, Willems J, DeGeest $H$. Relationship between the apexcardiogram and ventricular hemodynamics. In: Besse $P$, Bricaud $H$, eds. Performance ventriculaire gauche chez l'homme: symposium de la société internationale de cardiologie, 9-10 September 1973, Bordeaux. Paris: Expansion Scientifique, 1975: 173-83.

Requests for reprints to Dr P S Reddy, Cardiac Diagnostic Laboratories, 3411 PresbyterianUniversity Hospital, 230 Lothrop Street, Pittsburgh, Pennsylvania 15213, USA. 